\title{
Syndrome of ischaemic ocular inflammation: six cases and a review
}

\author{
N A JACOBS AND A E A RIDGWAY
}

From Manchester Royal Eye Hospital

SUMmaRY Patients with carotid occlusive disease may develop a variety of symptoms and signs secondary to chronic ocular ischaemia. We report six cases affecting nine eyes and review the findings of teichopsia, anterior segment ischaemia, venous stasis retinopathy, and ocular neovascularisation. The assessment and surgical management of carotid obstruction are discussed. Some comments on the relevance of coexisting diabetes are made.

\begin{abstract}
Although much attention has been paid to the acute ocular manifestations of carotid arterial disease, the chronic aspects have been less well reported. Retinal ischaemia is a more familiar concept than ischaemia of the eye as a whole.

The syndrome of ischaemic ocular inflammation described by Knox ${ }^{1}$ consists of amaurosis fugax, pain without photophobia, and marked reduction in visual acuity disproportionate to the degree of inflammation. The pupil is dilated, and the fundus shows midperipheral haemorrhages and arterial narrowing.

We discuss the manifestations of chronic ocular ischaemia in six patients with underlying carotid occlusive disease. Successful management may depend on expeditious identification and referral of these patients.
\end{abstract}

\section{Case reports}

CASE 1

A woman aged 39, a smoker and a hypertensive with a history of right-sided transient ischaemic attacks and angina, presented with a two-year history of blurred left vision. This followed an episode of amaurosis fugax. She also complained of pain and persisting after-images in this eye for two months. Visual acuity (VA) was 6/12, with mild anterior chamber activity and early formation of peripheral anterior synechiae (PAS). The fundus showed marked venous stasis with beading, haemorrhages,

Correspondence to Mr N A Jacobs, Department of Ophthalmology, Charing Cross Hospital, Fulham Palace Road, London W6 8RF. and microaneurysms (Fig. 1). Fine disc new vessels were present.

We saw her one month after the successful saphenous by-pass graft for a left common carotid artery occlusion which had been demonstrated on angiography (Fig. 2).

\section{CASE 2}

A man aged 55, a smoker, presented with a five-day history of a 'fierce pain' over the right eye associated with blurred vision. VA was $6 / 36$, with an unreactive dilated pupil, rubeosis of the angle, and an intraocular pressure (IOP) of $30 \mathrm{mmHg}$. Iris angiography confirmed ischaemia. There was also venous stasis retinopathy (Fig. 3) associated with cotton-wool spots. On review three months later episcleral injection, uveitis, and new vessels over the disc were also observed.

A left carotid bruit was heard. Angiography revealed occlusion of the right internal carotid artery and left internal carotid stenosis (Fig. 4). A left carotid endarterectomy was performed.

One year after the patient's initial presentation the right VA was perception of light (PL), with formation of a complicated cataract.

\section{CASE 3}

A man aged 67, a smoker and a hypertensive recovering from a right hemiparesis, presented with a six-month history of gradually deteriorating left vision. He also complained of pain over the left eye and a persisting after-image described as a 'jagged gold light'. His VA was counting fingers (CF), with episcleral injection, anterior chamber flare, early 


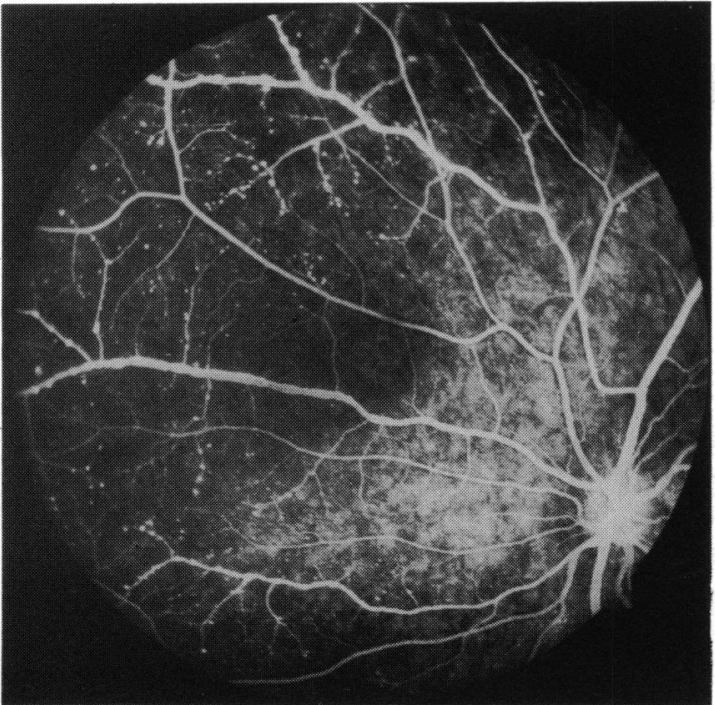

Fig. 1 Left fundus fluorescein angiogram (case 1) showing microaneurysms and venous beading.

rubeosis iridis, and an unreactive dilated pupil. Fundal examination showed venous stasis retinopathy and cotton-wool spots.

Carotid auscultation was hindered by an aortic valve murmur, but intravenous digital subtraction angiography showed arch atheroma with left common carotid artery occlusion.

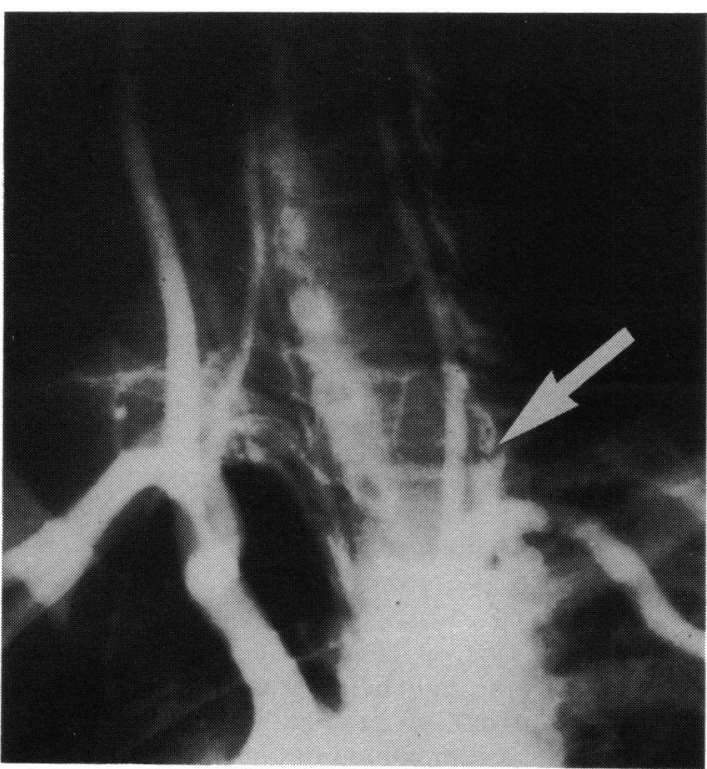

Fig. 2 Arch aortogram (case 1) showing occluded left common carotid artery (arrow).

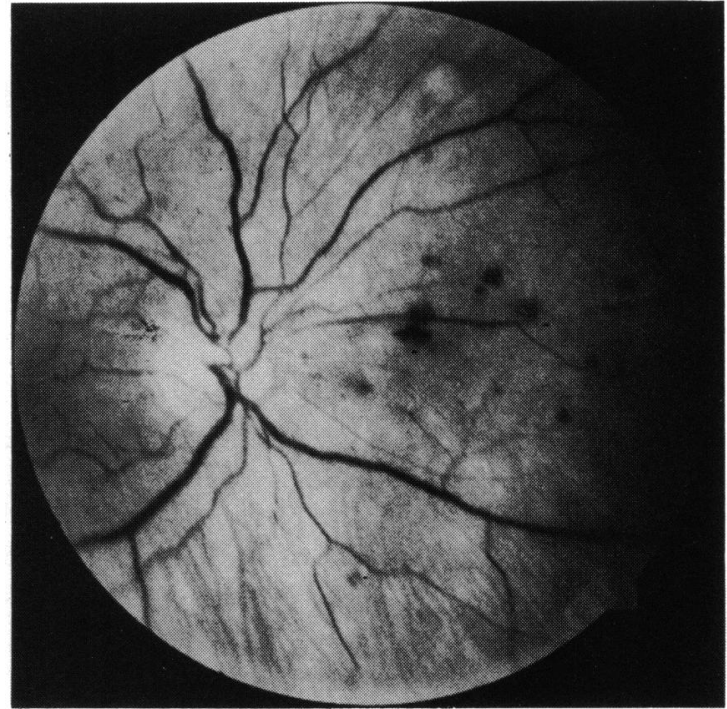

Fig. 3 Venous stasis retinopathy (case 2) well marked in nasal quadrant.

Eight months after the patient's initial presentation the left VA was PL, with a complicated cataract and rubeotic glaucoma. The IOP was $25 \mathrm{mmHg}$.

\section{CASE 4}

A man aged 66, a hypertensive recovering from a right hemiparesis, was found to be diabetic on

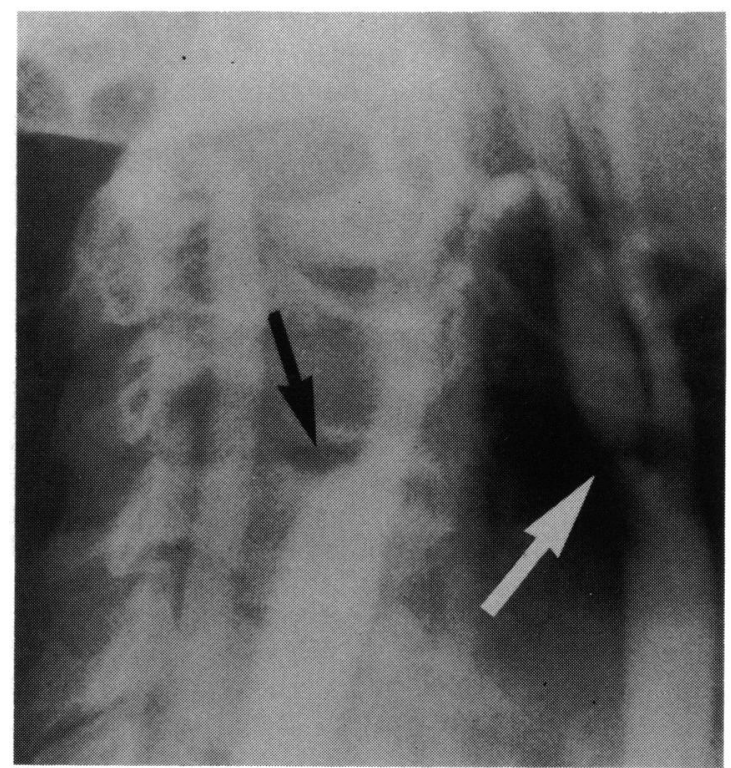

Fig. 4 Carotid angiography (case 2) shows right internal carotid occlusion (black arrow) with left internal carotid stenosis (white arrow). 
presentation. He complained of left-sided floaters following an episode of amaurosis fugax. His VA was $6 / 18$ right, $6 / 12$ left, with bilateral rubeosis iridis and IOPs of $20 \mathrm{mmHg}$ right, $24 \mathrm{mmHg}$ left. Both fundi showed only mild background diabetic change. In addition there was a left vitreous haemorrhage emanating from the disc.

Two months later he complained of pain over the left eye. His VA was CF, with anterior chamber flare and rubeotic glaucoma, with an IOP of $35 \mathrm{mmHg}$. A full retinal laser photocoagulation was carried out in this eye. After a further four months the VA on the right had fallen to $6 / 36$, and a right macular branch vein occlusion was noted. The left fundus showed the appearance of an old central retinal artery occlusion associated with a pale disc. Rubeosis iridis was marked bilaterally.

He was experiencing episodes of disorientation. Bilateral carotid bruits were noted, but intravenous digital subtraction angiography was not helpful.

Eighteen months after initial presentation his VA was hand movements right, PL left, with complicated cataracts and rubeotic glaucoma bilaterally (Fig. 5).

\section{CASE 5}

A man aged 55, a diabetic with hypertension and angina pectoris, presented with episodes of upper field amaurosis in his amblyopic right eye. His VA was $6 / 60$, with an upper macular branch artery occlusion. Six months later he complained of 'coloured lights' affecting central vision, precipitated by straining. Soon afterwards he returned with a right vitreous haemorrhage and disc new vessels. Episcleral injection, anterior uveitis with posterior synechiae, and early PAS were noted. Despite partial retinal laser photocoagulation, gross proliferative

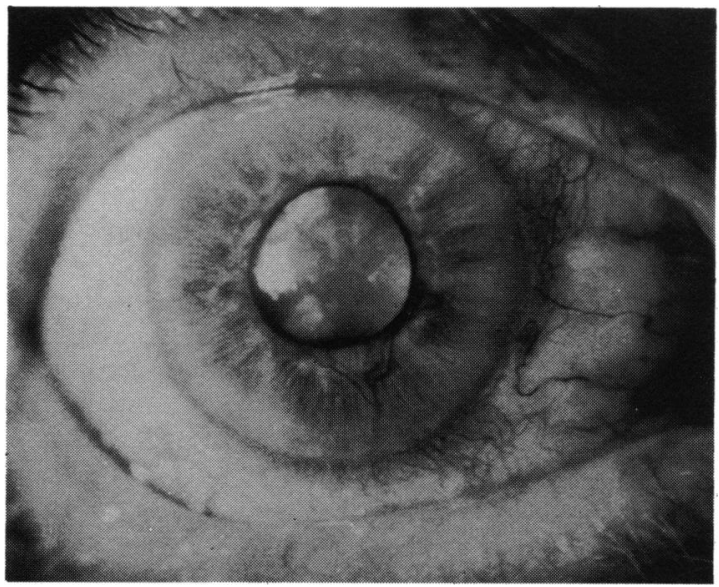

Fig. 5 End stage of rubeotic glaucoma with secondary cataract (case 4).

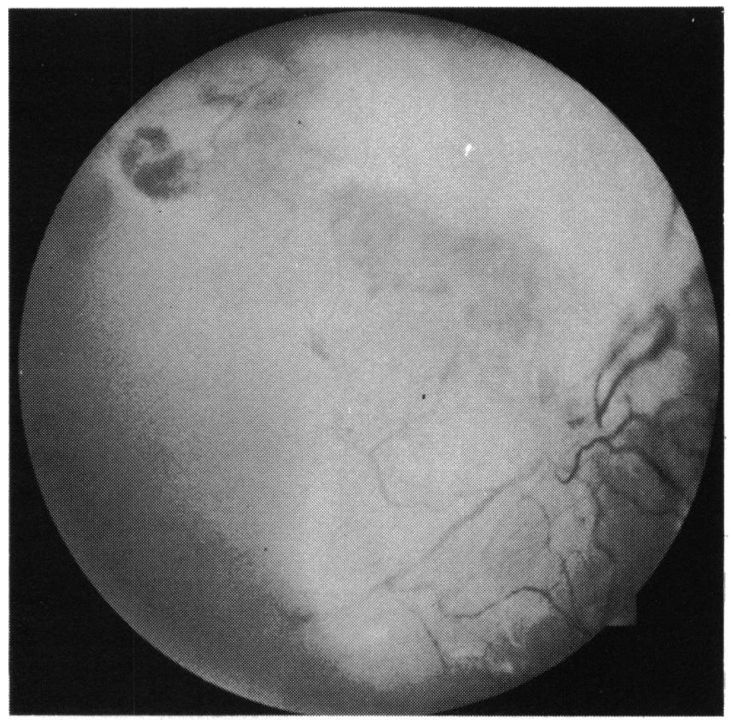

Fig. 6 Gross proliferative retinopathy (case 5) in diabetic patient whose fellow eye showed minimal change.

retinopathy with traction detachment ensued (Fig. 6). At around this time he suffered two leftsided hemipareses.

On review two years after his initial presentation he gave a history of persisting positive scotomata in the left eye, particularly on waking. His VA was $6 / 9$, and examination of this previously normal eye showed the appearance of venous stasis retinopathy.

Bilateral carotid bruits were detected. Angiography revealed occlusion of the right internal carotid artery, with tight stenoses of the left internal and external carotid arteries.

CASE 6

A man aged 77, a hypertensive and an ex-smoker, presented with episodes of left upper field amaurosis fugax and blurring of vision. He also complained of seeing bright flashes of light and persisting after-images likened to 'a bright map of Australia'. His VA was $6 / 5$ and no ocular abnormality was found. Fifteen months later he returned with a VA of $6 / 24$ in this eye. Fine rubeosis of the pupil margin, gross disc new vessels (Figs. 7A, B) and peripheral blot haemorrhages on the retina were apparent. A full retinal laser photocoagulation caused only a temporary regression of the disc new vessels. After a further three months he complained of blurred right vision, and this eye also showed venous stasis retinopathy with disc new vessels.

A right carotid bruit was heard. Carotid angiography showed bilateral internal carotid stenoses, more marked on the right, and in addition bilateral 


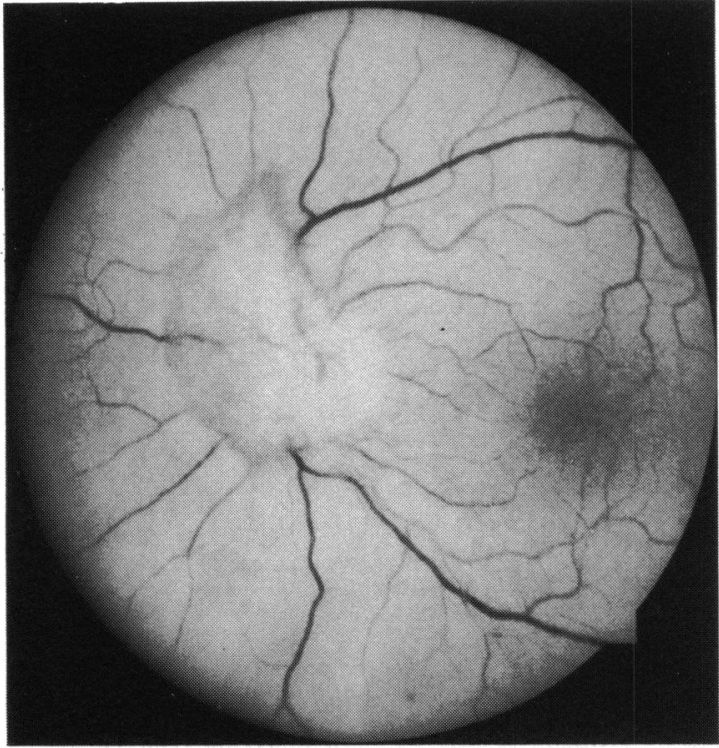

Fig. 7A Left red free photograph showing gross disc neovascularisation (case 6).

external carotid stenoses were present, more marked on the right (Fig. 8).

The case reports are summarised in Table 1.

\section{Discussion}

Because the time sequence of events is relatively short prompt investigation of patients presenting with symptoms and signs of chronic ocular ischaemia is desirable, as early intervention may offer hope of therapeutic effect. For this reason a high index of suspicion is necessary.

The visual symptom of note was the description of positive after-images on exposure to bright light, described variously by our patients as 'jagged gold lights', 'coloured lights', and 'a bright map of Australia'. Ross-Russell and Page ${ }^{2}$ have previously drawn attention to positive scotomata in patients with carotid artery obstruction. Furlan et al. ${ }^{3}$ reported five such patients who complained of blurring of vision after exposure to sunlight. Brindley, investigating positive after-images, concluded that after the first few seconds these were due to photochemical effects. Possibly choroidal vascular insufficiency leads to compromise of photoreceptor metabolism.

The signs of chronic anterior segment ischaemia have been well documented in the context of the changes seen after extensive extraocular muscle surgery. ${ }^{6}$ Our patients showed episcleral injection, anterior uveitis, and iris atrophy. Iris angiography

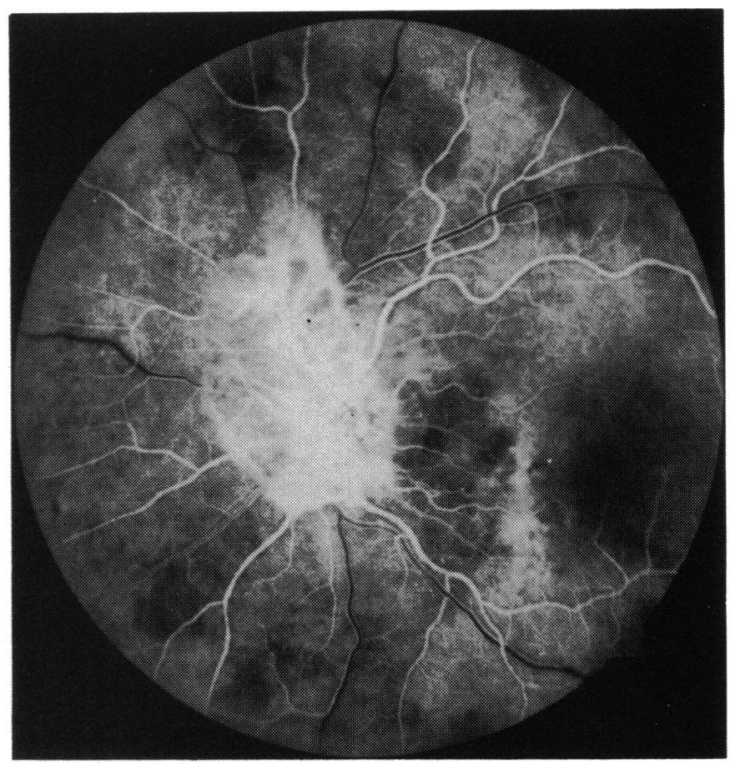

Fig. 7B Fluorescein angiogram shows leakage of disc new vessels associated with slow irregular choroidal filling.

confirmed ischaemia (case 2). Of six eyes with inflammatory signs four had rubeotic glaucoma, a sign which has not been reported after acute anterior segment ischaemia. ${ }^{5}$ Neovascularisation of the iris may follow release of vasoproliferative agents, anteriorly from chronically ischaemic iris and posteriorly from ischaemic retina and choroid. ${ }^{7}$ The eyes with rubeosis had relatively low IOPs $(25-35 \mathrm{mmHg})$, which we think are explained by low perfusion pressures ${ }^{1}$ causing reduced ciliary body blood flow. Pain in this syndrome ${ }^{189}$ is probably related to ischaemia rather than to increase of IOP.

Venous stasis retinopathy, described by Kearns and Hollenhorst ${ }^{9}$ and consisting of venous dilatation, microaneurysms (Fig. 1), and blossom haemorrhages (Fig. 3), is the commonest ocular sign of chronic ischaemia in carotid obstruction, reported in up to $20 \%^{910}$ of cases.

The haemorrhages are larger and darker than those of diabetic retinopathy, are found in the midperiphery, and may be limited to one quadrant. In addition cotton-wool spots may be seen. Disc neovascularisation (Fig. 7) has been described more recently ${ }^{8}$ as a response to chronic ischaemia of the retina and choroid (Fig. 7B). Diabetic patients present special diagnostic difficulty, for early stasis retinopathy is difficult to recognise. Important clues are marked asymmetry of retinopathy ${ }^{\mathrm{B}}$ (Fig. 6) and gross disproportion in the extent of anterior and posterior segment pathology (case 4).

Earlier reports of chronic ocular ischaemia showed 
most patients to have aortic arch disease, with loss of peripheral pulses "1 due to atheroma, Takayashu's pulseless disease,,$^{1213}$ or syphilitic aortitis. In our patients the major factor was atheroma affecting the carotid systems. Four of them had central nervous system involvement consistent with carotid artery disease, three of them having had a completed stroke. Amaurosis fugax is the commonest ocular symptom of carotid occlusive disease, and was described by four patients. The manifestations of chronic ocular ischaemia are far less common, and, although they may coexist, patients presenting with amaurosis fugax are not particularly likely to develop chronic ischaemic signs.

Many diagnostic techniques are available for carotid investigation. Ophthalmodynamometry and ocular plethysmography assess carotid artery patency by measurement of the ophthalmic artery pulse pressure. The latter is the more useful test if bilateral lesions are present. ${ }^{14}$ The dynamic response to carotid artery compression may be monitored tonographically. ${ }^{15}$ Continuous wave Doppler ${ }^{16}$ is helpful in establishing whether a significant stenosis is present at the carotid bifurcation, and has the advantage of being non-invasive. Real-time ultrasound ${ }^{16}$ can reveal the presence of atheromatous plaques even if they do not have a significant haemodynamic effect. If no carotid artery lesions are present, or if the patients have cardiac arrhythmias, cardiac echography ${ }^{17}$ should be carried out to exclude emboli of cardiac origin. Arteriography is the most reliable method of demonstrating carotid artery lesions, but this carries a complication rate of up to $3.7 \% .^{18}$ Intravenous digital subtraction angiography is safer and has been reported in as many as $96 \%{ }^{18}$ of selected cases to show a lesion at the carotid bifurcation.

Our findings were similar to those of Brown et al. ${ }^{8}$ There was either common carotid occlusion on the affected side (Fig. 2) or bilateral internal carotid obstruction (Fig. 4). The patients with bilateral ocular involvement showed a combination of internal and external carotid stenoses (Fig. 8). The pattern of carotid disease seems to be aetiologically important in the development of chronic ocular ischaemia. Huckman and Haas ${ }^{19}$ have reported two cases in which there was reversal of flow in the ophthalmic artery, and have suggested there may be a 'steal' syndrome. However, this reversal of flow is a common finding in internal carotid obstruction, and one of our patients (case 6) has orthograde flow in the left and retrograde flow in the right ophthalmic artery, yet shows bilateral ocular ischaemia.

Stenosis of the origin of the internal carotid artery can be relieved by endarterectomy. However, internal carotid occlusion cannot be dealt with in this way, as retrograde thrombosis up to the level of the ophthalmic artery occurs. By taking advantage of the external carotid supply it may instead be by-passed with an anastomosis of the superficial temporal artery to a carotid branch of the middle cerebral artery. ${ }^{20}$

Table 1 Summary of the case reports

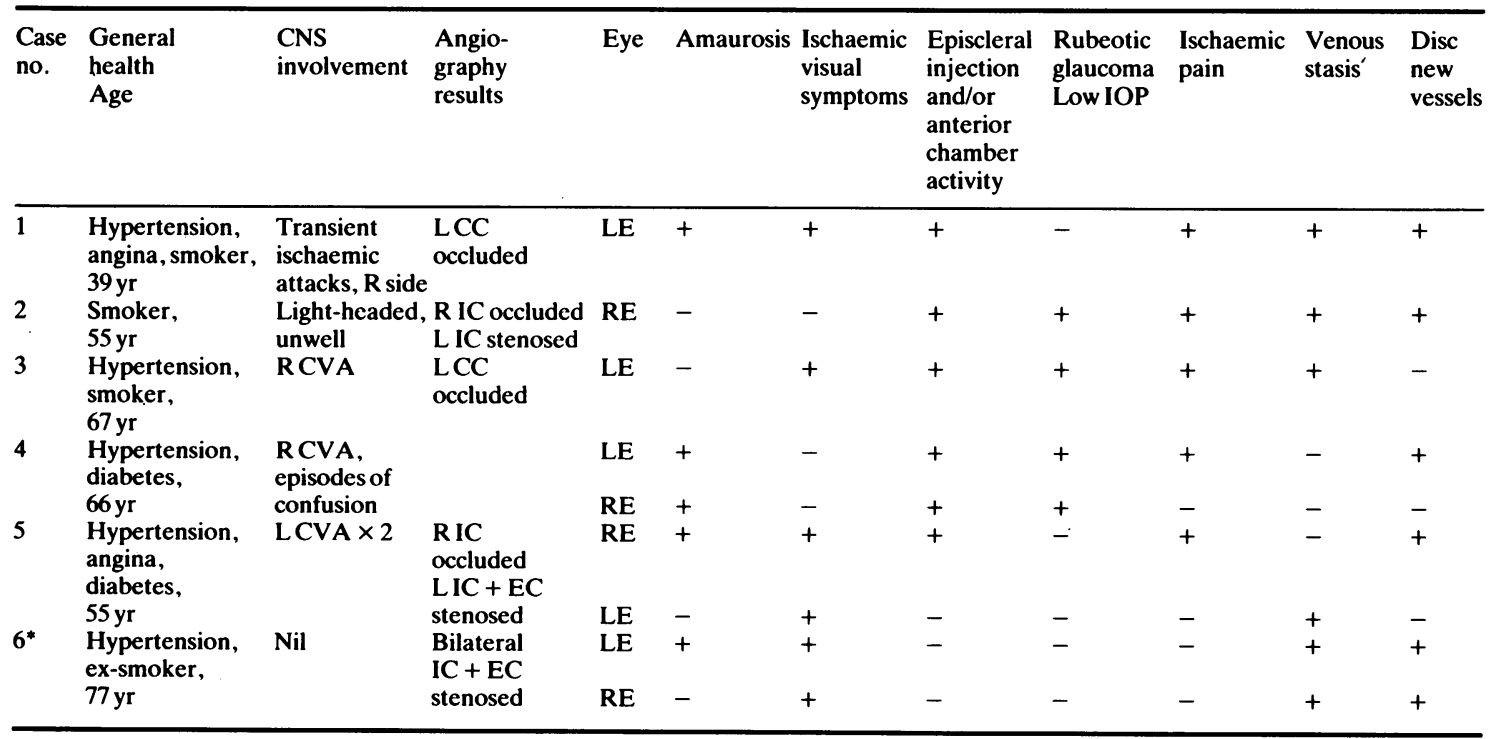

*This patient's left eye showed fine rubeosis of the pupil margin. CNS = central nervous system. CVA=cerebrovascular accident. $\mathrm{CC}=$ common carotid artery. $\mathrm{IC}=$ internal carotid artery. $\mathrm{EC}=$ external carotid artery. 


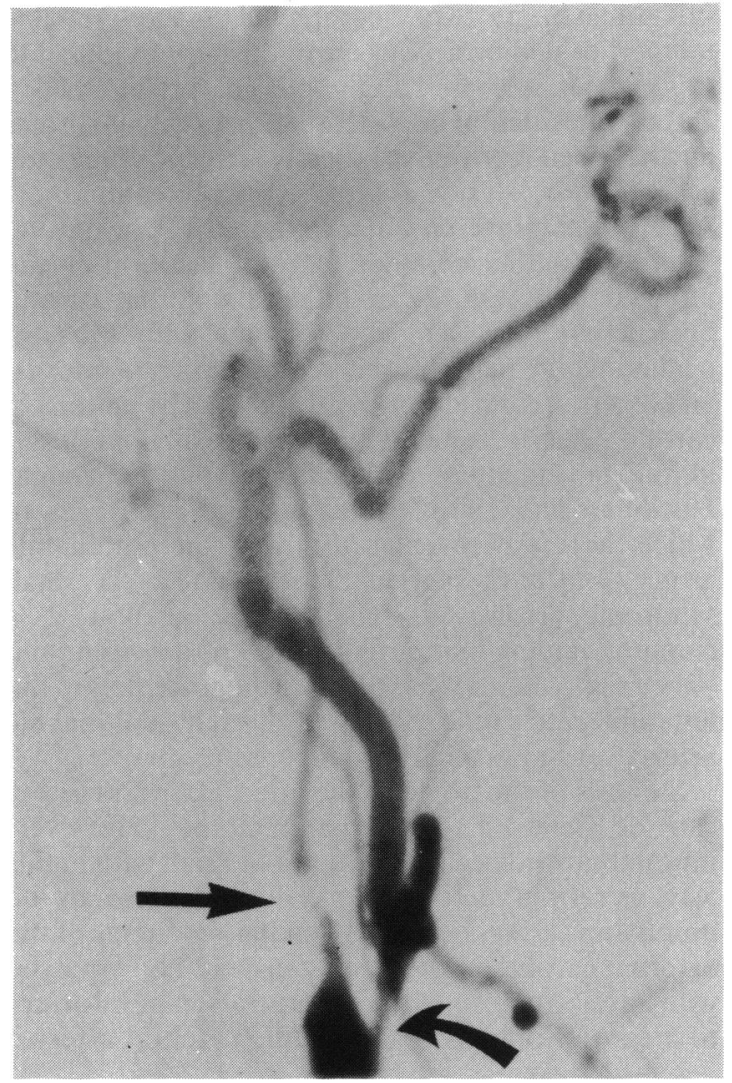

Fig. 8 Subtraction angiogram (case 6) showing right internal (straight arrow) and external carotid stenoses (curved arrow).

This may not be feasible if the external carotid artery itself is also severely affected. Several case reports of successful by-pass surgery for the relief of ocular ischaemia have been published. ${ }^{1021-23}$

Laser retinal photocoagulation was ineffective in the treatment of disc neovascularisation in our patients. The possibility exists that in established rubeosis, given that ischaemia can be relieved surgically, trabeculectomy may control ocular hypertension, as can occur in the management of diabetic neovascular glaucoma. ${ }^{24}$ By the end stage of this syndrome with rubeotic glaucoma, secondary cataract (Fig. 5) and probably occult central retinal artery occlusion, ${ }^{8}$ nothing can be done except for the relief of ischaemic pain, ${ }^{10}$ Recorded attempts at lens extraction ${ }^{12}$ show this to be unsuccessful.

The syndrome of ocular inflammation secondary to chronic ischaemia is uncommon, and neither ophthalmologists nor other specialists dealing with patients with carotid artery disease have much experience of the condition. Its diagnosis is made more difficult because it causes a plethora of signs and has to be differentiated from other causes of decreased visual acuity, ocular pain, teichopsia, anterior uveitis, rubeotic glaucoma, retinal venous dilatation with haemorrhages, and disc new vessel formation. Early recognition of the syndrome of chronic ocular ischaemia is important because there is now hope of useful improvement by reconstructive vascular surgery in the initial stages, while treatment later on fails to halt progression of the disease.

We extend our thanks to Lynn Griffin for her secretarial assistance, to the Department of Retinal Photography at Manchester Royal Eye Hospital, and to the Department of Medical Illustration at Manchester Royal Infirmary.

\section{References}

1 Knox DL. Ischemic ocular inflammation. Am J Ophthalmol 1965; 60: 995-1002.

2 Ross-Russell RW, Page NGR. Critical perfusion of brain and retina. Brain 1983; 106: 419-34.

3 Furlan AJ, Whisnant JP, Kearns TP. Unilateral visual loss in bright light. Arch Neurol 1979; 36: 657-6.

4 Brindley GS. The discrimination of after images. J. Physiol (Lond) 1959; 147: 194-203.

5 Girard LJ, Beltravena F. Early and late complications of extensive muscle surgery. Arch Ophthalmol 1960; 64: 576-84.

6 Von Noorden GK. Anterior segment ischemia following the Jensen procedure. Arch Ophthalmol 1976; 94: 845-7.

7 Federman JL, Brown GL, Felberg NT, Felton SM. Experimental ocular angiogenesis. Am J Ophthalmol 1980; 89: 231-7.

8 Brown GC, Magangal LM, Simeone FA, Goldberg RE, Federman JL, Benson WE. Arterial obstruction and ocular neovascularization. Ophthalmology (Rochester) 1982; 89: $139-46$.

9 Kearns TP, Hollenhorst RW. Venous stasis retinopathy of occlusive disease of the carotid artery. Mayo Clin Proc 1963; 38: 304-12.

10 Kearns TP, Siebert RG, Sundt TM. The ocular aspects of by-pass surgery of the carotid artery. Mayo Clin Proc 1979; 54: 3-11.

11 Tour RL, Hoyt WF. Ocular manifestations of 'pulseless disease' and a report of a surgically treated case. Am J Ophthalmol 1959; 47: $35-48$.

12 Ostler HB. Pulseless disease (Takayashu's disease). Am J Ophthalmol 1957; 43: 583-9.

13 Leonard TJK, Sanders MD. Ischaemic optic neuropathy in pulseless disease. BrJ Ophthalmol 1983; 67: 389-92.

14 Weibers DO, Folger N, Forbes GS, Younge BR, O'Fallon WM. Ophthalmodynamometry and ocular pneumoplethysmography for detection of carotid occlusive disease. Arch Neurol 1982; 39: 690-1.

15 Percival SPB, Ridgway AEA. Carotid compression tonography: a new test for carotid insufficiency. Br Med J 1968; i: 357-8.

16 Jones AM, Biller J, Cowley AR, Howard G, McKinney WM, Toole JF. Extracranial carotid artery arteriosclerosis. Diagnosis with continuous wave doppler and real time ultrasound studies. Arch Neurol 1982; 39: 393-4.

17 Donaldson RM, Ballester M. Cardiac masses-detection by two dimensional echocardiography. $\mathrm{Br} J$ Hosp Med 1981; 25: 596-600.

18 Campo RV, Aaberg TM. Digital subtraction angiography in the diagnosis of retinal vascular disease. Am J Ophthalmol 1983; 96: 632-40.

19 Huckman MS, Haas J. Reversed flow through the ophthalmic artery as a cause of rubeosis iridis. Am J Ophthalmol 1972; 74: 1094-9. 
20 Yasargil MG. Diagnosis and indications for operations in cerebrovascular occlusive disease. In: Yasargil MG, ed. Michmory applied to neurosurgery. Stuttgart: Theime, 1969: 95-115.

21 Kearns TP, Younge BR, Piepgras DG. Resolution of venous stasis retinopathy after carotid artery by-pass surgery. Mayo Clin Proc 1980; 55: 342-6.

22 Edwards MS, Chater NL, Stanley JA. Reversal of chronic ocular ischaemia by extracranial-intracranial arterial by-pass: case report. Neurosurgery 1980; 7: 480-3.

23 Neupert JR, Brubuker RF, Kearns TP, Sundt TM. Rapid resolution of venous stasis retinopathy after carotid endarterectomy. Am J Ophthalmol 1976; 81: 600-2.

24 Flanagan DW, Blach RK. Place of panretinal photocoagulation and trabeculectomy in the management of neovascular glaucoma. Br J Ophthalmol 1983; 67: 526-8. 